Journal of Animal and Veterinary Advances 11 (7): 975-978, 2012

ISSN: $1680-5593$

(C) Medwell Journals, 2012

\title{
Meat Quality of Thai Indigenous Chickens Raised Indoors or with Outdoor Access
}

\author{
Paphapin Puttaraksa, Wittawat Molee and Sutisa Khempaka \\ School of Animal Production Technology, Institute of Agricultural Technology, \\ Suranaree University of Technology, 30000 Nakhon Ratchasima, Thailand
}

\begin{abstract}
The objective of this study was to determine the effect of rearing system on meat quality of Thai indigenous chickens. Three hundred and sixty 1 day old chicks were randomly allocated into 2 treatments: indoor treatment, housing in an indoor pen $\left(5 \mathrm{birds} / \mathrm{m}^{2}\right)$ or outdoor access treatment, housing in an indoor pen ( $5 \mathrm{birds} / \mathrm{m}^{2}$ ) with access to a grass paddock $\left(1 \mathrm{bird} / \mathrm{m}^{2}\right)$ from 8 weeks of age until slaughter. All birds were provided with the same diet during the experimental period. At 16th weeks of age, 24 birds per treatment were slaughtered to evaluate the quality of breast and thigh meat. The results showed that there was no difference in nutrient composition of breast meat among treatments ( $p>0.05$ ). However, thigh meat from outdoor access treatment had higher protein content than that of indoor treatment $(\mathrm{p}<0.05)$. There was no difference in drip loss of breast and thigh meat among treatments $(\mathrm{p}>0.05)$. Breast and thigh meat from outdoor access treatment had a higher shear force value $(\mathrm{p}=0.05)$ than from indoor treatment. Thigh meat from outdoor access treatment was higher in soluble, insoluble and total collagen contents compared with indoor treatment $(\mathrm{p}<0.05)$. Breast and thigh meat from outdoor access treatment was less red $\left(a^{*} ; p<0.05\right)$ and more yellow $\left(b^{*} ; p<0.05\right)$ than those from indoor treatment. Breast skin from outdoor access treatment had more yellow than that of indoor treatment $(\mathrm{p}<0.05)$. The data indicated that Thai indigenous chickens raised with outdoor access could significantly increase shear value and collagen content in meat and increase yellow color in breast skin.
\end{abstract}

Key words: Rearing system, free-range, Thai indigenous chicken, meat quality, breast skin, chicken

\section{INTRODUCTION}

Thai indigenous chicken meat has a unique taste and is more delicious than commercial broiler meat. Demand for Thai indigenous chicken meat is generally higher than supply and the price is about two times higher than that of commercial broilers. However, most of Thai indigenous chickens are raised by rural households under minimum feed and management; consequently their growth rate and feed efficiency are very poor. The production of Thai indigenous chickens can be improved if they are raised by the conventionally confined system. But rearing in high stocking density in an indoor house leads to the problem of feather pecking damage because Thai indigenous chickens have the traits of fighting cocks. This behavior is considered as one of the major economic and welfare problems in the chicken industry.

A study of suitable rearing system could lead to improved efficiency in Thai indigenous chicken production. The previous study Molee et al. (2011) found that the outdoor access system had no effect on growth performance and carcass composition compared with the indoor system but could reduce the feather pecking damage of Thai indigenous chickens. This result suggested that Thai indigenous chickens can be produced with a system of outdoor access (a free-range system) which would serve the needs of consumers who are interested in natural chicken products and which would add value to the product for Thai indigenous chicken producers.

Recently very little information has been available regarding the meat quality of Thai indigenous chickens raised by the free-range system. Previous studies in Europe (Lewis et al., 1997; Castellini et al., 2002; Gordon and Charles, 2002) reported that meat quality of chicken from free-range or organic systems is more appropriate for a specialized market. Therefore, the outdoor access system seems to be a good alternative method due to better welfare conditions and the better quality of the chicken meat. The purpose of this study was to determine the effect of the rearing system on meat quality traits of Thai indigenous chickens.

\section{MATERIALS AND METHODS}

Animals, diets and management: A total of 360 , days old straight-run Thai indigenous chicks were randomly allocated into 2 groups; for indoor and outdoor access

Corresponding Author: Wittawat Molee, School of Animal Production Technology, Institute of Agricultural Technology, Suranaree University of Technology, 30000 Nakhon Ratchasima, Thailand 
treatments, respectively. Each treatment was represented by 6 replications with 30 birds in each. In the indoor treatment, birds were placed in pens of open housed ( 5 birds $/ \mathrm{m}^{2}$ ). In the outdoor access treatment, birds were placed in an indoor house $\left(5 \mathrm{birds} / \mathrm{m}^{2}\right)$ in addition, they also had access to an outdoor grass paddock ( $1 \mathrm{bird} / \mathrm{m}^{2}$ ). In this system, birds were kept under the covered area from $6 \mathrm{pm}$ to $6 \mathrm{am}$ and had free access to pasture after 8 weeks of age. Birds of both systems were fed ad libitum the same diet without animal ingredient sources, antibiotics or growth promotants. The ingredients and nutrient composition of the experimental diets is shown in Table 1.

Sample collection: At 16 weeks, after fasting for $10 \mathrm{~h}, 24$ birds were randomly selected from each treatment. All birds were weighed individually and killed by manual exsanguination and thereafter the birds were manually eviscerated. After chilling for $24 \mathrm{~h}$, breast meat (Pectoralis major) and thigh meat were collected for an analysis of meat quality.

Sample analytical determinations: Moisture, protein and fat contents of raw breast and thigh meat were measured following AOAC (1995) methodology. Drip loss percentage was measured on raw meat samples. Breast and thigh meat samples were trimmed at both ends and weighed before and after storage. The samples were hung on a hook in a refrigerator for $24 \mathrm{~h}$ at $4^{\circ} \mathrm{C}$ in an absorption

Table 1: Ingredient composition and calculated analy sis of the experimental diets (as fed basis)

\begin{tabular}{lccc}
\hline Ingredients (\%) & $0-3$ weeks & $3-6$ weeks & $6-16$ weeks \\
\hline Corn & 38.55 & 46.65 & 55.30 \\
Soybean meal & 25.85 & 25.60 & 23.50 \\
Full fat soybean meal & 16.00 & 9.00 & 4.50 \\
Rice bran & 10.00 & 10.00 & 10.00 \\
Palm oil & 5.45 & 5.00 & 3.00 \\
Salt & 0.25 & 0.25 & 0.25 \\
Calcium carbonate & 1.55 & 1.60 & 1.80 \\
Dicalcium phosphate & 1.50 & 1.00 & 0.90 \\
DL-Methionine & 0.35 & 0.25 & 0.20 \\
L-Lysine & 0.00 & 0.15 & 0.05 \\
Premix & 0.50 & 0.50 & 0.50 \\
Calculated nutrient composition & & & \\
Energy (kcal of ME kg ${ }^{-1}$ ) & $3,100.00$ & $3,100.00$ & $3,100.00$ \\
Dry matter (\%) & 90.50 & 90.30 & 90.10 \\
Crude protein (\%) & 21.00 & 19.00 & 17.00 \\
Fat (\%) & 11.36 & 9.89 & 8.42 \\
Crude fiber (\%) & 4.57 & 4.38 & 4.18 \\
Ash (\%) & 5.45 & 5.20 & 4.82 \\
Calcium & 1.00 & 0.90 & 0.80 \\
Available phosphorus (\%) & 0.45 & 0.35 & 0.30 \\
\hline
\end{tabular}

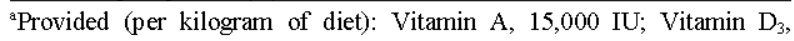
3,000 IU; Vitamin E, $25 \mathrm{IU}$; Vitamin $\mathrm{K}_{3}, 5 \mathrm{mg}$; Vitamin $\mathrm{B}_{1}, 2.5 \mathrm{mg}$; Vitamin $B_{2}, 7 \mathrm{mg}$; Vitamin $\mathrm{B}_{6}, 4.5 \mathrm{mg}$; Vitamin $\mathrm{B}_{12}, 25 \mu \mathrm{g}$; Pantothenic acid, $35 \mathrm{mg}$; Folic acid, $0.5 \mathrm{mg}$; Biotin, $25 \mu \mathrm{g}$; Nicotinic acid, $35 \mathrm{mg}$; Choline chloride, $250 \mathrm{mg}$; $\mathrm{Mn}, 60 \mathrm{mg}$; $\mathrm{Zn}, 45 \mathrm{mg}$; Fe, $80 \mathrm{mg}$; Cu, $1.6 \mathrm{mg}$; I, $0.4 \mathrm{mg} ; \mathrm{Se}, 0.15 \mathrm{mg}$ pad and put into polyethylene bags. Drip loss percentage was calculated as: (Weight before storage-Weight after storage)/Initial weight $\times 100$. Shear force was measured on cooked breast and thigh meat according to the method of Dawson et al. (1991) using a TA-XT2 Texture Analyzer (Godalming, UK) with a Warner-Bratzler shear apparatus. The operating parameters consisted of a cross-head speed of $2 \mathrm{~mm} \mathrm{sec}^{-1}$ and a $5 \mathrm{~kg}$ load cell. Collagen determinations were performed by a 3-step procedure allowing the separation of soluble and insoluble collagen as described by Hill (1966). Separation was performed by centrifugation (Rotina $35 \mathrm{R}$, Hettich Zentrifugen, Tuttilingen, Germany) at $5,200 \times \mathrm{g}$ for $26 \mathrm{~min}$. After hydrolysis, the 2 fractions of hydroxyproline were detected at a $558 \mathrm{~nm}$ wavelength with a spectrophotometer (Thermo Electron Corporation, Genesys 10-UV scanning, Madison, USA) as described by Bergman and Loxley (1963). The collagen content was expressed as milligrams of collagen per gram of meat. Color (Lightness, $L^{*}$; redness, $a^{*}$; yellowness, $b^{*}$ ) was measured on raw breast meat, thigh meat, breast skin and thigh skin. The meat samples were put into vacuum polyethylene bags for chilling for $24 \mathrm{~h}$ at $4^{\circ} \mathrm{C}$ before color measurement using a Colorimeter (Chroma Meter CR-300, Minolta, Japan).

Statistical analysis: Data collected in completely randomized design were subjected to an analysis of variance and treatment means were compared using Duncan's multiple range test. SPSS for Windows (Release 10) (SPSS Inc., Chicago, IL) was used for statistical analysis.

\section{RESULTS AND DISCUSSION}

The effects of rearing system on nutrient composition of Thai indigenous chicken meat are shown in Table 2. There was no significant difference among treatments for dry matter, protein and fat contents in breast meat ( $p>0.05$ ). This agrees with Wang et al. (2009) although, Fanatico et al. (2007) and Husak et al. (2008) found that the outdoor chickens had increased protein content in breast meat compared with the indoor chickens.

Table 2: Effect of rearing system on nutrient composition of Thai indigenous chicken meat

\begin{tabular}{lrccc}
\hline Nutrient (\%) & Indoor & Outdoor access & p-value & Pooled SE \\
Breast meat & & & & \\
Dry matter & 26.21 & 26.28 & 0.91 & 0.10 \\
Protein & 24.18 & 24.61 & 0.38 & 0.07 \\
Fat & 1.59 & 1.69 & 0.60 & 0.03 \\
Thigh meat & & & & \\
Dry matter & 24.52 & 26.03 & 0.01 & 0.08 \\
Protein & 20.45 & 21.39 & 0.01 & 0.05 \\
Fat & 3.18 & 3.07 & 0.67 & 0.04 \\
\hline
\end{tabular}


The outdoor chickens had higher dry matter and protein contents in thigh meat than the indoor chickens $(p<0.05)$. However, fat content in thigh meat was not significantly different among treatments $(p>0.05)$. This observation is in consistent with Husak et al. (2008) in the case of protein and fat contents but they found that dry matter content was not different among free-range and conventional chickens. Many factors affect the nutrient composition of meat including genetics, feed ingredients and physical activity (Zerehdaran et al., 2004; Cangar et al., 2007; Rizzi et al., 2007). Thai indigenous chickens are slow-growing genotypes which have more locomotion. Previous study (Castellini et al., 2002) showed that greater motion favored muscle mass development. In the present study although, there was no difference in protein content of breast meat among treatments but the outdoor chickens had higher protein content in thigh meat than the indoor chickens which is possibly related to exercise in an outdoor access area contributing to muscle development and higher protein. Juiciness and tenderness are two very important factors when it comes to meat quality.

Percentage drip loss is often regarded as an indication of the juiciness of meat. If the drip loss value is high, meat products will lack juiciness. The effects of rearing system on drip loss, shear force and collagen contents of Thai indigenous chicken meat are shown in Table 3. There was no significant difference among treatments for drip loss of breast and thigh meat ( $>0.05)$. This result is in consistent with Wang et al. (2009) but in contrast with Castellini et al. (2002) and Fanatico et al. (2007) found that the outdoor chickens had higher drip loss than the indoor chickens. Shear force is regarded as an indication of the tenderness of meat. If shear value is high, meat products will be tougher. The results showed that outdoor chickens had higher shear force in breast and thigh meat than indoor chickens $(\mathrm{p}=0.05)$. This agrees with Castellini et al. (2002) as a consequence of

Table 3: Effect of rearing system on drip loss, shear force and collagen contents of Thai indigenous chicken meat

\begin{tabular}{|c|c|c|c|c|}
\hline Items & Indoor & Outdoor access & p-value & Pooled SE \\
\hline \multicolumn{5}{|l|}{ Breast meat } \\
\hline Drip loss (\%) & 6.53 & 7.93 & 0.12 & 0.130 \\
\hline Shear force $\left(\mathrm{g} \mathrm{mm}^{-1}\right)$ & 188.76 & 210.34 & 0.05 & 1.250 \\
\hline \multicolumn{5}{|l|}{ Collagen $\left(\mathrm{mg} \mathrm{g}^{-1}\right)$} \\
\hline Soluble & 0.60 & 0.56 & 0.01 & 0.002 \\
\hline Insoluble & 1.36 & 1.34 & 0.79 & 0.010 \\
\hline Total collagen & 1.95 & 1.89 & 0.45 & 0.010 \\
\hline \multicolumn{5}{|l|}{ Thigh meat } \\
\hline Drip loss (\%) & 7.74 & 8.92 & 0.24 & 0.140 \\
\hline Shear force $\left(\mathrm{g} \mathrm{mm}^{-1}\right)$ & 233.47 & 253.99 & 0.05 & 0.020 \\
\hline \multicolumn{5}{|l|}{ Collagen $\left(\mathrm{mg} \mathrm{g}^{-1}\right)$} \\
\hline Soluble & 0.69 & 0.73 & 0.02 & 0.003 \\
\hline Insoluble & 1.81 & 2.08 & $<0.01$ & 0.010 \\
\hline Total collagen & 2.50 & 2.69 & $<0.01$ & 0.010 \\
\hline
\end{tabular}

greater motion activity. In addition, Farmer et al. (1997) reported that the breast meat from chickens reared under lower stocking density had higher shear force value than those reared under high stocking density. But in contrast, Wang et al. (2009) found that there was no difference in the shear force value between free-range and conventional chickens. Collagen content is believed to greatly influence meat toughness. Torrescano et al. (2003) found a positive relationship between shear force of raw samples and total collagen content $(\mathrm{r}=0.72)$ and insoluble collagen ( $\mathrm{r}=0.66)$ of beef and Nishimura et al. (2009) found a positive correlation $(\mathrm{r}=0.72)$ between total collagen and shear force of raw pork. The present study showed that thigh meat from outdoor chickens was higher in soluble, insoluble and total collagen contents compared with indoor chickens $(\mathrm{p}<0.05)$, consequently their shear force value was higher. However, insoluble and total collagen contents of breast meat was not significantly different among treatments $(p>0.05)$ whereas the outdoor chickens had lower soluble collagen content in breast meat than indoor chickens $(\mathrm{p}<0.05)$.

Color is one of the first characteristics noticed by consumers when buying meat products (Fanatico et al., 2007). The effects of rearing system on meat and skin color of Thai indigenous chickens are shown in Table 4. Breast and thigh meat from outdoor chickens was less red $\left(a^{*} ; \mathrm{p}<0.05\right)$ and more yellow $\left(b^{*} ; \mathrm{p}<0.05\right)$ than those from indoor chickens. However, outdoor chickens had paler thigh meat $\left(\mathrm{L}^{*} ; \mathrm{p}<0.05\right)$ than indoor chickens while no difference was found among treatments for lightness of color in breast meat $(\mathrm{p}>0.05)$. In previous studies, Castellini et al. (2002) found that an organic system with outdoor access resulted in higher lightness and yellowness values in breast and thigh meat compared with an indoor system while Husak et al. (2008) found there

Table 4: Effect of rearing system on meat and skin color of Thai indigenous

\begin{tabular}{lrccc}
\multicolumn{1}{c}{ chickens } & \multicolumn{3}{c}{ Pooled SE } \\
\hline Items & Indoor & Outdoor access & p-value & \\
\hline Meat color & & & & \\
Breast meat & & & & \\
$\mathrm{L}^{*}$ & 71.08 & 71.98 & 0.15 & 0.09 \\
$\mathrm{a}^{*}$ & 2.76 & 1.47 & 0.01 & 0.07 \\
$\mathrm{~b}^{*}$ & 8.32 & 11.88 & $<0.01$ & 0.15 \\
Thigh meat & & & & \\
$\mathrm{L}^{*}$ & 67.77 & 73.08 & 0.01 & 0.15 \\
$\mathrm{a}^{*}$ & 3.52 & 2.44 & 0.01 & 0.05 \\
$\mathrm{~b}^{*}$ & 4.21 & 4.82 & 0.03 & 0.14 \\
Skin color & & & & \\
Breast skin & & & & \\
$\mathrm{L}^{*}$ & 67.77 & 70.28 & 0.13 & 0.24 \\
$\mathrm{a}^{*}$ & 1.72 & 1.87 & 0.69 & 0.05 \\
$\mathrm{~b}^{*}$ & 2.03 & 3.69 & 0.03 & 0.11 \\
Thigh skin & & & & \\
$\mathrm{L}^{*}$ & 63.15 & 65.71 & 0.05 & 0.19 \\
$\mathrm{a}^{*}$ & 6.51 & 6.95 & 0.64 & 0.13 \\
$\mathrm{~b}^{*}$ & 0.58 & 1.25 & 0.30 & 0.09 \\
\hline
\end{tabular}


was higher redness in thigh meat and lower yellowness in both breast and thigh meat. Thigh skin from outdoor chickens was paler than that of indoor chickens $(p=0.05)$ but there was no significant difference among treatments in redness and yellowness $(\mathrm{p}>0.05)$. Breast skin from outdoor chickens was more yellow than that of indoor chickens $(p<0.05)$ which is possibly related to foraging and the consequent ingestion of pigments from plants. However, there was no significant difference among treatments for lightness and redness $(p>0.05)$. These differences in the color of meat and skin may be related to the differences in the environmental conditions for each study.

\section{CONCLUSION}

In this study, the outdoor access or free-range system was found to significantly increase shear value and collagen content in meat and increase the yellow color of breast skin. Although, the meat quality showed some differences between the two treatments, the outdoor access system seems to be a good alternative method due to better welfare conditions. This product will serve the needs of consumers who are interested in natural chicken products and it will also add value to the product for Thai indigenous chicken producers. Further experiments are needed to determine the effects of a free-range system on fatty acid composition and the cholesterol content of Thai indigenous chicken meat.

\section{ACKNOWLEDGEMENTS}

The researchers would like to thank the office of the National Research Council of Thailand and Suranaree University of Technology for providing funding for this research.

\section{REFERENCES}

AOAC, 1995. Official Methods of Analysis. 16th Edn., Association of Official Analytical Chemists, Washington, DC., USA.

Bergman, I. and R. Loxley, 1963. Two improved and simplified methods for the spectrophotometeric determination of hydroxyproline. Anal. Chem., 35: 1961-1965.

Cangar, O., J.M. Aerts, E. Vranken and D. Berckmans, 2007. Online growth control as an advance in broiler farm management. Poult. Sci., 86: 439-443.

Castellini, C., C. Mugnai and A. Dal-Bosco, 2002. Effect of organic production system on broiler carcass and meat quality. Meat Sci., 60: 219-225.

Dawson, P.L., B.W. Sheldon and J.J. Miles, 1991. Effect of aseptic processing on the texture of chicken meat. Poult. Sci., 70: 2359-2367.
Fanatico, A.C., P.B., Pillai, J.L. Emmert and C.M. Owens, 2007. Meat quality of slow-and fast-growing chicken genotypes fed low-nutrient or standard diets and raised indoors or with outdoor access. Poult. Sci., 86: $2245-2255$.

Farmer, L.J., G.C. Perry, P.D. Lewis, G.R. Nute, J.R. Piggott and R.L.S. Patterson, 1997. Responses of two genotypes of chicken to the diets and stocking densities of conventional UK and label rouge production systems. II. Sensory attributes. Meat Sci., 47: 77-93.

Gordon, S.H. and D.R. Charles, 2002. Niche and Organic Chicken Products. 1st Edn., Nottingham University Press, Nottingham, UK.

Hill, F., 1966. The solubility of intramuscular collagen in meat animals in various ages. J. Anim. Sci., 31: 161-166.

Husak, R.L., J.G. Sebranek and K. Bregendahl, 2008. A survey of commercially available broilers originating from organic, free-range and conventional production systems for meat yield, composition and relative value. Poult. Sci., 87: 2367-2376.

Lewis, P.D., G.C. Perry, L.J. Farmer and R.L.S. Patterson, 1997. Responses of two genotypes of chicken to the diets and stocking densities typical of UK and Label Rouge production systems: I. Performance, behaviour and carcass composition. Meat Sci., 45: 501-516.

Molee, W., P. Puttaraksa, S. Pitakwong and S. Khempaka, 2011. Performance, carcass yield, hematological parameters and feather pecking damage of thai indigenous chickens raised indoors or with outdoor access. Proc. World Acad. Sci. Eng. Technol., 80: 646-649.

Nishimura, T., S. Fang, J. Wakamatsu and K. Takahashi, 2009. Relationships between physical and structural properties of intramuscular connective tissue and toughness of raw pork. Anim. Sci. J., 80: 85-90.

Rizzi, C., A. Marangon and G.M. Chiericato, 2007. Effect of genotype on slaughtering performance and meat physical and sensory characteristics of organic laying hens. Poult. Sci., 86: 128-135.

Torrescano, G., A. Sanchez-Escalante, B. Gimenez, P. Roncales and J.A. Beltran, 2003. Shear values of raw samples of 14 bovine muscles and their relation to muscle collagen characteristics. Meat Sci., 64: $85-91$.

Wang, K.H., S.R. Shi, T.C. Dou and H.J. Sun, 2009. Effect of a free-range raising system on growth performance, carcass yield and meat quality of slow-growing chicken. Poult. Sci., 88: 2219-2223.

Zerehdaran, S., A.L. Vereijken, J.A. van Arendonk and E.H. van der Waaijt, 2004. Estimation of geneti parameters for fat deposition and carcass trits in broilers. Poult. Sci., 83: 521-525. 